\title{
Light Scattering Study on the Structure of Pure Polystyrene
}

\author{
Michiya FUJIKI and Shigeru OIKAWA \\ Component and Material Development Division, Ibaraki Electrical \\ Communication Laboratory, Nippon Telegraph and Telephone \\ Public Corporation, Tokai, Ibaraki, 319-11, Japan
}

(Received January 26, 1984)

\begin{abstract}
An unusual temperature dependence of light scattering properties by pure polystyrene (PS) was observed in the temperature range of $30-170^{\circ} \mathrm{C}$ : the $V_{\mathrm{v}}^{\prime}$ and $V_{\mathrm{v}}^{\text {iso }}$ intensities minimized near $T_{\mathrm{g}}$, and the $H_{\mathrm{v}}^{\prime}$ intensity changed with measuring temperatures. These phenomena can be explained by "the scrambling effects of incident and scattered light" during transmission through the sample, as previously pointed out for PS glass by Claiborne and Crist. The PS sample used was prepared by a very careful procedure in which the evaporable monomer, initiator, and chain transfer agent were distilled in a closed vacuum system and in situ polymerization was carried out above $T_{\mathrm{g}}$. The corrected $V_{\mathrm{v}}^{\text {iso }}$ intensity for PS glass was favorably compared with the values calculated from the thermal density fluctuation, indicating that PS glass was in a frozen state near $T_{\mathrm{g}}$. The corrected $H_{\mathrm{v}}$ intensity for PS glass was nearly equal to the heretofore calculated value, assuming a randomly oriented anisotropic liquid for PS. Our experimental results showed no evidence for an ordered structure in pure PS glass, as is found in pure poly(methyl methacrylate) glass, but PS rubber has a partially oriented state.

KEY WORDS Light Scattering / Polystyrene / Fluctuation / Local Structure /

Amorphous Polymer / Scrambling Effects /
\end{abstract}

Poly(methyl methacrylate) (PMMA) and polystyrene (PS), typical amorphous polymers, are quite transparent in the visible and nearinfrared region. These polymers have been used as plastic optical fibers (POFs). However, commercial PMMA core POFs have large losses of about $7.0 \times 10^{-4} \mathrm{~cm}^{-1}(650 \mathrm{~nm}){ }^{1} \mathrm{Re}-$ cently, we obtained, by a modified vacuum distillation procedure, low-loss POFs with an attenuation loss of $2.05 \times 10^{-4} \mathrm{~cm}^{-1}$ (522 and $570 \mathrm{~nm}$ ) for a PMMA core fiber ${ }^{2}$ and $2.62 \times$ $10^{-4} \mathrm{~cm}^{-1}(672 \mathrm{~nm})$ for a PS core fiber. ${ }^{3}$ This procedure allowed PMMA and PS fibers to be highly purified both optically and chemically. ${ }^{3}$ To clarify the cause for optical loss and the theoretical attenuation limits for PMMA and PS, it is very important to examine these polymers by light scattering.

The local structure of polymer molecules in the amorphous state is now a subject of con- siderable current interest and controversy. ${ }^{4-7}$ Two different kinds of models, the random coil model and bundle model, have been proposed. In the random coil model, it is assumed that the amorphous phase is homogeneous and random in structure. ${ }^{4}$ In the bundle model, it is assumed that the amorphous state is homogeneous and anisotropic on a molecular level. ${ }^{5-7}$ A number of light and X-ray scattering experiments have been reported for PMMA, ${ }^{8-18}$ PS $^{16-24}$ and other amorphous polymers. ${ }^{25-28}$ For PMMA and PS glass, it remains less clear as to which model is relevant.

Excess light scattering intensities are invariably found in PMMA glasses and attributed to the existence of semicrystalline region, internal frozen strains, low molecular weight species, microinhomogeneities or dust. Recently, from a light scattering study on 
PMMA glasses prepared by MMA monomer distillation, Judd and $\mathrm{Crist}^{8}$ concluded that PMMA has an intrinsic structure of about $800 \AA$ dimensions. In a previous paper, we reported that no evidence could be found for an ordered structure in pure PMMA glass and liquid from the temperature dependence of light scattering. ${ }^{14}$ This may be attributable to the very carefully prepared sample used, closed vacuum distillation using an evaporable monomer and additives, the in situ polymerization above $T_{\mathrm{g}}$, and the relative low molecular weight of polymer controlled by an appropriate chain transfer agent.

Previous analyses of the angular dependence of the light and X-ray scattered intensity for PS glasses, commercially available or prepared by monomer filtration, show the presence of rather large heterogeneities (ca. 1000$4000 \AA$ ). It has generally been supposed that such heterogeneities are due to an ordered region, solid impurities, and unreacted monomer. Dettenmaier and Fischer ${ }^{16}$ reported the absence of an orientational correlation for the carefully prepared PS sample. Claiborne and $\mathrm{Crist}^{23}$ indicated that light and X-ray scattering are not so sensitive to the structure of small isotropic regions and depolarised light scattering may be more sensitive to the structure of an ordered region through orientational correlations, but a quantitative interpretation of the $H_{\mathrm{v}}$ component is difficult. They also demonstrated polarized and depolarized light scattering studies to be influenced by polarization scrambling of incident and scattered light during transmission through PS glass. ${ }^{22}$ Nevertheless, they concluded that no structure was present other than that expected in a supercooled liquid for pure PS glass prepared by monomer distillation and in situ thermal polymerization, since light scattering was found to be unaffected by thermal history.

In this paper, we demonstrate an unusual temperature dependence near $T_{\mathrm{g}}$ for the polarized and depolarized components of light scattering by pure PS sample, while Dettenmaier and Fischer ${ }^{15}$ observed the depolarized component for PS to be independent of the measuring temperature and thermal history. We also consider the ordered structure in PS to be determined by the temperature dependence of light scattering in the glassy and rubbery states. The PS sample preparation was carried out with particular care, a polymerization above $T_{\mathrm{g}}$ using both evaporable polymerization initiator and a chain transfer agent and a relative low molecular weight polymer sample controlled by an appropriate chain transfer agent.

\section{EXPERIMENTAL}

The styrene monomer (St) was prepared by the following process. First, polymerization inhibitors were eliminated by rinsing with alkali. The residual alkali was then removed by washing with pure water until the $\mathrm{pH}$ of the system was neutral. After being dried by the addition of $\mathrm{Na}_{2} \mathrm{SO}_{4}$ and $\mathrm{CaH}_{2}$, the monomer was carefully distilled under reduced pressure in a stream of Ar gas, and a center fraction was collected (bp $70-72^{\circ} \mathrm{C} / 130 \mathrm{mmHg}$ ).

Di-tert-butyl peroxide (DBPO) chosen as the initiator was carefully distilled under reduced pressure (bp $46.5-47.8^{\circ} \mathrm{C} / 80 \mathrm{mmHg}$ ). 2-Methyl-2-propanethiol (MPT) was used as a chain transfer agent to depress auto-acceleration effects (bp $64-66^{\circ} \mathrm{C} / 760 \mathrm{mmHg}$ ). Diphenylpycrylhydrazil (DPPH) was used as a polymerization inhibitor during the sample preparation.

St containing $1.0 \times 10^{-2} \mathrm{M}$ DBPO, $5.0 \times$ $10^{-2} \mathrm{M}$ MPT, and $1.0 \times 10^{-2} \mathrm{M}$ DPPH was poured into ampoule $\mathrm{A}$ in the apparatus shown in Figure 1, and degassed under $0.1 \mathrm{mmHg}$, taking care to prevent dust and oxygen from entering the ampoule. Part $\mathrm{C}$ was then sealed. Ampoules A and B were maintained at 70 and $0^{\circ} \mathrm{C}$, respectively. Ampoule B, with optically polished internal and external walls, was $20 \mathrm{~mm}$ in diameter and $200 \mathrm{~mm}$ in 


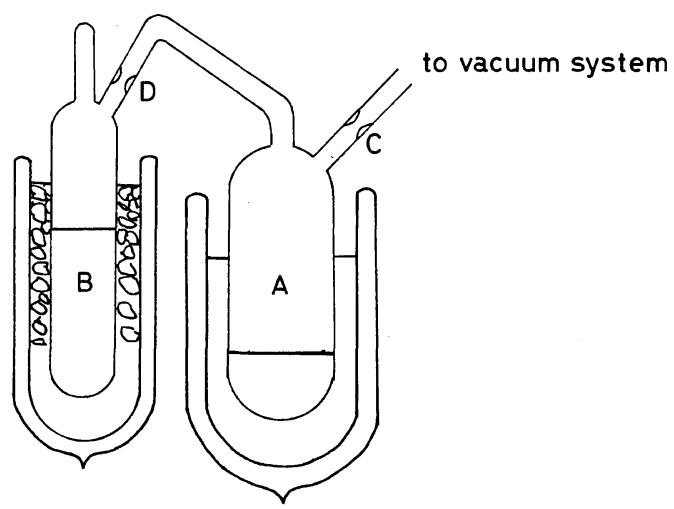

Figure 1. Apparatus for purifying the St solution used in the vacuum distillation sample preparation.

length. After distillation, the entire assembly was shaken, and the St containing the additives in ampoule $\mathrm{B}$ was transfered to ampoule $\mathrm{A}$, and ampoule $\mathrm{B}$ was washed. After this process was repeated several times, no glittering due to optical impurities, such as dust and large particles, were detected at all when the $\mathrm{He}-\mathrm{Ne}$ laser beam was passed through ampoule B. Finally, ampoule B containing pure $\mathrm{St}$ was sealed at part $\mathrm{D}$, and the polymerization of MMA was allowed to proceed for $48 \mathrm{~h}$ at $120^{\circ} \mathrm{C}$, for $12 \mathrm{~h}$ at $140^{\circ} \mathrm{C}$, and then for $2 \mathrm{~h}$ at $160^{\circ} \mathrm{C}$. From GPC measurements, the weight-average molecular weight of the polymer sample was found to be $4.5 \times 10^{4}$ and the polydispersity index to be $M_{w} / M_{n}=2.2$.

The light scattering apparatus was described in our previous paper. ${ }^{14}$ In this study, a relatively low power $\mathrm{He}-\mathrm{Ne}$ laser $(0.95 \mathrm{~mW}$, $633 \mathrm{~nm}$ ) was used and prevented local heating in the sample due to the 6th order $\mathrm{C}-\mathrm{H}$ stretching vibration of PS (ca. $8-9 \times 10^{-6}$ $\left.\mathrm{cm}^{-1,3}\right)$.

\section{RESULTS AND DISCUSSION}

To determine the density fluctuation and anisotropy fluctuation, polarized $\left(V_{\mathrm{v}}\right.$ and $\left.H_{\mathrm{h}}\right)$ and depolarized $\left(H_{\mathrm{v}}\right.$ and $\left.V_{\mathrm{h}}\right)$ intensities were calculated from the following equations on the assumption that $H_{\mathrm{v}}=V_{\mathrm{h}}=H_{\mathrm{h}}$ for a randomly oriented spheroid ${ }^{30,31}$ :

$$
\begin{gathered}
R_{90}=\frac{V_{\mathrm{v}}+V_{\mathrm{h}}+H_{\mathrm{v}}+H_{\mathrm{h}}}{2}=\frac{V_{\mathrm{v}}+3 H_{\mathrm{v}}}{2} \\
\rho_{\mathrm{u}}=\frac{V_{\mathrm{h}}+H_{\mathrm{h}}}{V_{\mathrm{v}}+H_{\mathrm{v}}}=\frac{2 H_{\mathrm{v}}}{V_{\mathrm{v}}+H_{\mathrm{v}}} \\
V_{\mathrm{v}}=V_{\mathrm{v}}^{\text {iso }}+\frac{4}{3} H_{\mathrm{v}}=R_{90} \frac{2-\rho_{\mathrm{u}}}{1+\rho_{\mathrm{u}}} \\
V_{\mathrm{v}}^{\text {iso }}=R_{90} \frac{2-\frac{7}{3} \rho_{\mathrm{u}}}{1+\rho_{\mathrm{u}}} \\
H_{\mathrm{v}}=R_{90} \frac{\rho_{\mathrm{u}}}{1+\rho_{\mathrm{u}}}
\end{gathered}
$$

where $V_{\mathrm{v}}$ and $H_{\mathrm{v}}$ are the vertical and horizontal components of the scattered light intensity for vertically polarized incident light, $V_{\mathrm{h}}$ and $H_{\mathrm{h}}$ the corresponding quantities for horizontally polarized incident light, and $V_{\mathrm{v}}^{\text {iso }}$ the isotropic part of the $V_{\mathrm{v}}$ component. The values for $V_{\mathrm{v}}, V_{\mathrm{v}}^{\text {iso }}$, and $H_{\mathrm{v}}$ could be evaluated by substituting the measured $R_{90}$ and $\rho_{\mathrm{u}}$ into eq $3-5$.

The $V_{\mathrm{v}}^{\text {iso }}$ and $H_{\mathrm{v}}$ of light scattered by a structureless liquid was calculated from the following equations ${ }^{31,32}$ :

$$
\begin{gathered}
V_{\mathrm{v}}^{\text {iso }}=\frac{\pi^{2}}{9 \lambda_{0}^{4}}\left(n^{2}-1\right)^{2}\left(n^{2}+2\right)^{2} k T \beta \\
H_{\mathrm{v}}=\frac{16 \pi^{2}}{135 \lambda_{0}^{4}}\left(n^{2}+2\right)^{2} N_{0} \gamma_{0}^{2}
\end{gathered}
$$

For polymer glass and liquid, eq 6 gives the polarized scattering resulting from thermal density fluctuation as a function of the wavelength $\lambda_{0}$ of incident light in a vacuum, the average refractive index $n$, the Boltzmann constant $k$, the absolute temperature $T$ of liquid or glass, and the isothermal compressibility $\beta$ at $T_{\mathrm{g}}$. Equation 7 gives the depolarized scattering arising from the meansquare polarizability anisotropy $\gamma_{0}^{2}$ of scattering centers. For polymers, $N_{0}$ is the number of monomer repeat units. ${ }^{9}$ 


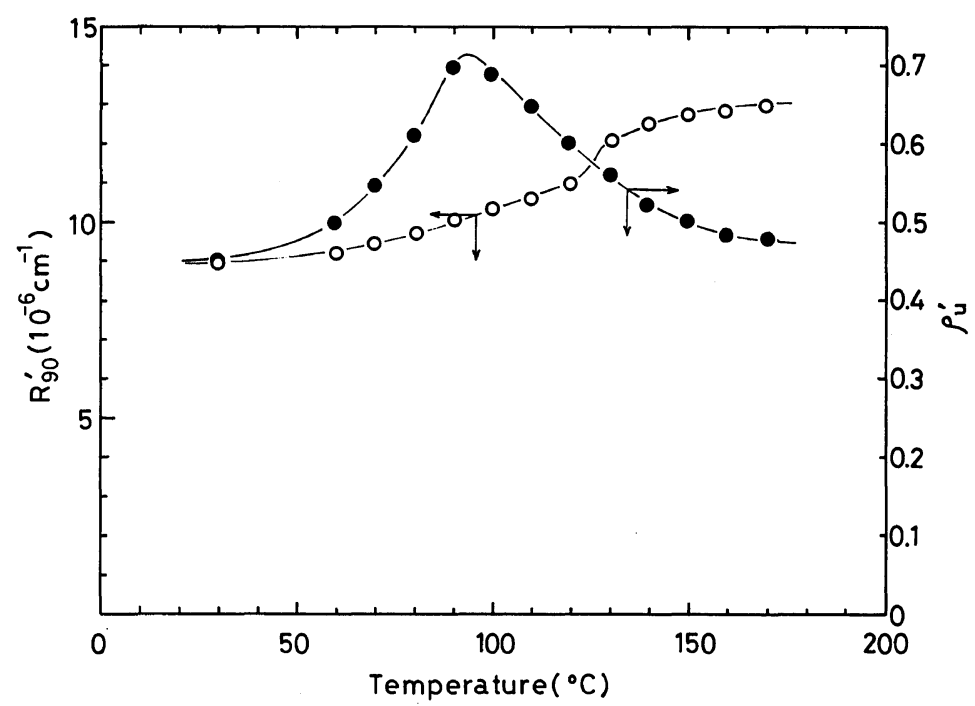

Figure 2. Temperature dependence of apparent $R_{90}^{\prime}$ and $\rho_{\mathrm{u}}^{\prime}$ values for pure PS $\left(\lambda_{0}=633 \mathrm{~nm}\right)$.

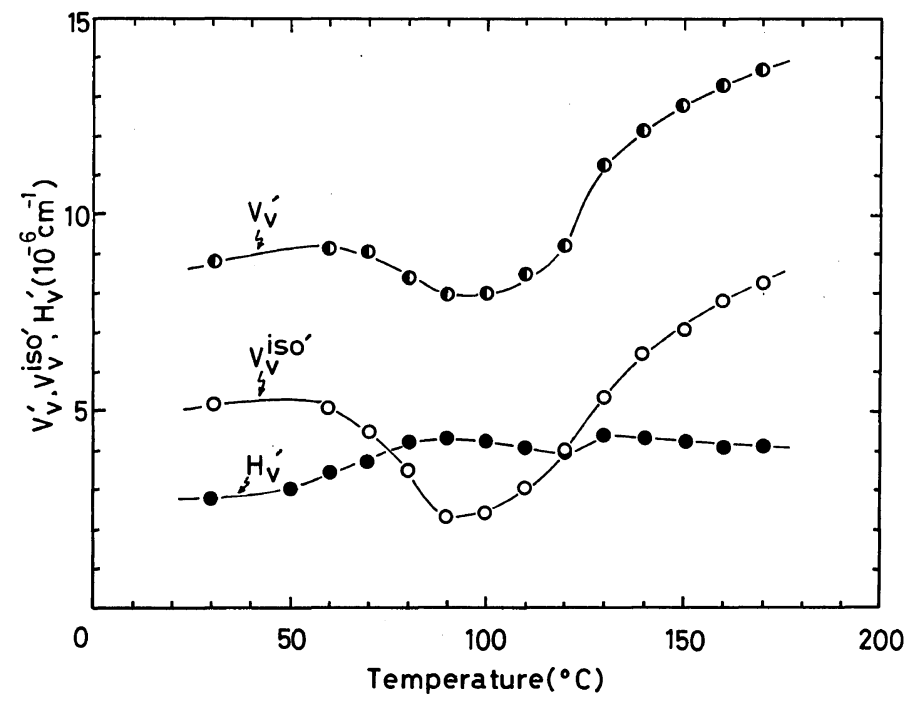

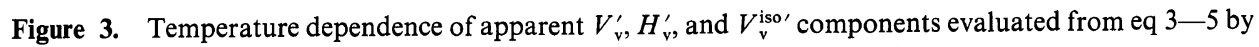
using $R_{90}^{\prime}$, and $\rho_{\mathrm{u}}^{\prime}$ measured at each temperature for pure PS $\left(\lambda_{0}=633 \mathrm{~nm}\right)$.

The observed values of $R_{90}^{\prime}$ and $\rho_{\mathrm{u}}^{\prime}$ for pure PS, differing from the intrinsic values of $R_{90}$ and $\rho_{\mathrm{u}}$ due to "the scrambling effect;" are shown as functions of temperature in Figure 2. The $R_{90}^{\prime}$ intensity decreases smoothly with decreasing temperature from 170 to $110^{\circ} \mathrm{C}$ near $T_{\mathrm{g}}$ of PS $\left(100^{\circ} \mathrm{C}\right)$, and undergoes a small change from 90 to $30^{\circ} \mathrm{C}$. The $\rho_{\mathrm{u}}^{\prime}$ shows a maximum near $T_{\mathrm{g}}$ and decreases above and below $T_{\mathrm{g}}$. Variations in $R_{90}^{\prime}$ and $\rho_{\mathrm{u}}^{\prime}$ with temperature were quite reversible above $T_{\mathrm{g}}$ when the temperature was changed slowly.

The observed $V_{\mathrm{v}}, V_{\mathrm{v}}^{\text {iso }}$, and $H_{\mathrm{v}}$ components, $V_{\mathrm{v}}^{\prime}, V_{\mathrm{v}}^{\text {iso' }}$, and $H_{\mathrm{v}}^{\prime}$, evaluated from $R_{90}^{\prime}$ and $\rho_{\mathrm{u}}^{\prime}$ 
at each temperature are shown in Figure 3. An unusual temperature dependence for $V_{\mathrm{v}}^{\prime}, V_{\mathrm{v}}^{\text {iso, }}$, and $H_{\mathrm{v}}^{\prime}$ intensities was found. Thus far, two groups of investigators studied the temperature dependence of the thermal density and anisotropy fluctuation by light scattering and SAXS for PS. Dettenmaier and Fischer investigated the polarised and depolarized light scattering for a purified PS sample ${ }^{16}$ and found the $V_{\mathrm{v}}^{\text {iso }}$ intensity to decrease smoothly with decreasing temperature to $T_{\mathrm{g}}$ but remained virtually invariable below $T_{\mathrm{g}}$, and the $H_{\mathrm{v}}$ intensity to be nearly constant both above and below $T_{\mathrm{g}}$. Ruland ${ }^{17}$ studied density fluctuation in commercial PMMA and PS in the range from 0 to $400 \mathrm{~K}$ using SAXS and found the fluctuation vs. $T$ curve of these polymers to show breaks at $T_{\mathrm{g}}$. Above $T_{\mathrm{g}}$, the fluctuation obeyed the relationship valid for a system in thermodynamic equilibrium, while below $T_{\mathrm{g}}$, the fluctuation decreased more slowly, approaching a non-zero value at $0 \mathrm{~K}$ with decreasing $T$. The trends of the $V_{\mathrm{v}}^{\prime}-T, V_{\mathrm{v}}^{\text {iso' }}-T$ and $H_{\mathrm{v}}^{\prime}-T$ curves obtained in the present experiment differ from the results of Dettenmaier and Fischer, ${ }^{16}$ and Ruland. ${ }^{17}$ The reason for this may be "the scrambling effects of incident and scattered light beam," as pointed out by Claiborne and Crist. ${ }^{22,23}$ In their report, ${ }^{22,23}$ these effects were associated with inhomogeneous stress and resulting strain birefringence. They found the PS sample, adhering to the sample tube, to scramble the incident polarized radiation. We wish to explain this unusual temperature dependence of $V_{\mathrm{v}}^{\prime}$, $V_{\mathrm{v}}^{\text {iso' }}, H_{\mathrm{v}}^{\prime}$ by scrambling effects, since $V_{\mathrm{v}}^{\text {iso' }}$ intensities near $T_{\mathrm{g}}$ decreased by $60 \%$, compared with those heretofore calculated and observed.

A rather simple model based on this scrambling can be used to account for the experimental results. It is assumed that the linearly polarized beam is scrambled after travelling half way through the sample, and thus can be represented by two orthogonal components $I_{\mathrm{z}}=I_{0}$ and $I_{\mathrm{y}}=(1-\alpha) I_{0}$. The

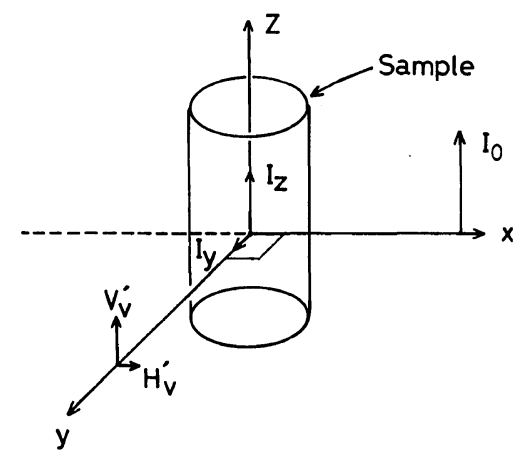

Figure 4. Model of scrambling effects of incident and scattered light during transmission through the sample.

scrambled light is a mixture of natural light and linearly polarized light, as illustrated for vertically polarized incident radiation in Figure 4. After a scattering has occurred in the center of the sample, the apparent $V_{\mathrm{v}}, H_{\mathrm{v}}, V_{\mathrm{h}}$, and $H_{\mathrm{h}}$ components, $V_{\mathrm{v}}^{\prime}, H_{\mathrm{v}}^{\prime}, V_{\mathrm{h}}^{\prime}$ and $H_{\mathrm{h}}^{\prime}$, can be given by $V_{\mathrm{v}}, H_{\mathrm{v}}, V_{\mathrm{h}}, H_{\mathrm{h}}$, and $\alpha$.

$$
\begin{aligned}
& V_{\mathrm{v}}^{\prime}=\alpha^{2} V_{\mathrm{v}}+\alpha(1-\alpha)\left(H_{\mathrm{v}}+V_{\mathrm{h}}\right)+(1-\alpha)^{2} H_{\mathrm{h}} \\
& H_{\mathrm{v}}^{\prime}=\alpha^{2} H_{\mathrm{v}}+\alpha(1-\alpha)\left(V_{\mathrm{v}}+H_{\mathrm{h}}\right)+(1-\alpha)^{2} V_{\mathrm{h}} \\
& V_{\mathrm{h}}^{\prime}=\alpha^{2} V_{\mathrm{h}}+\alpha(1-\alpha)\left(V_{\mathrm{v}}+H_{\mathrm{h}}\right)+(1-\alpha)^{2} H_{\mathrm{v}} \\
& H_{\mathrm{h}}^{\prime}=\alpha^{2} H_{\mathrm{h}}+\alpha(1-\alpha)\left(H_{\mathrm{v}}+V_{\mathrm{h}}\right)+(1-\alpha)^{2} V_{\mathrm{v}}
\end{aligned}
$$

These expression can be rewritten as follows, assuming that $H_{\mathrm{v}}=V_{\mathrm{h}}=H_{\mathrm{h}}$ for intrinsic random polymers.

$$
\begin{aligned}
& V_{\mathrm{v}}^{\prime}=\alpha^{2} V_{\mathrm{v}}+\left(1-\alpha^{2}\right) H_{\mathrm{v}} \\
& H_{\mathrm{v}}^{\prime}=\left(\alpha^{2}-\alpha+1\right) H_{\mathrm{v}}+\alpha(1-\alpha) V_{\mathrm{v}} \\
& V_{\mathrm{h}}^{\prime}=\left(\alpha^{2}-\alpha+1\right) H_{\mathrm{v}}+\alpha(1-\alpha) V_{\mathrm{v}} \\
& H_{\mathrm{h}}^{\prime}=\alpha(2-\alpha) H_{\mathrm{v}}+(1-\alpha)^{2} V_{\mathrm{v}}
\end{aligned}
$$

We thus obtain the apparent depolarization factor, $\rho_{\mathrm{u}}^{\prime}$, connected with $V_{\mathrm{v}}, H_{\mathrm{v}}$, and $\alpha$, as follows;

$$
\rho_{\mathrm{u}}{ }^{\prime}=\frac{(1-\alpha) V_{\mathrm{v}}+(1+\alpha) H_{\mathrm{v}}}{\alpha V_{\mathrm{v}}+(2-\alpha) H_{\mathrm{v}}}
$$

In discussing scrambling effects, it should be pointed out that the apparent total $R_{90}$ value, $R_{90}^{\prime}$, is unchanged with $\alpha$. A simulation of the 
dependence of $\rho_{\mathrm{u}}^{\prime}$ is shown in Figure 5. From this figure, $\rho_{\mathrm{u}}^{\prime}$ increases with decreasing $\alpha=1$ to 0 .

To obtain $\alpha$, we assume the following: (1) No scrambling effects occur at 30 and $170^{\circ} \mathrm{C}$, that is, at the temperatures $\alpha=1$ and $\rho_{\mathrm{u}}^{\prime}=\rho_{\mathrm{u}}$, since the values of $\rho_{\mathrm{u}}^{\prime}$ seem to approach a constant value at 30 and $170^{\circ} \mathrm{C}$. (2) Below $T_{\mathrm{g}}$, the values of $V_{\mathrm{v}}^{\text {iso }}$ and $H_{\mathrm{v}}$ increase more slowly

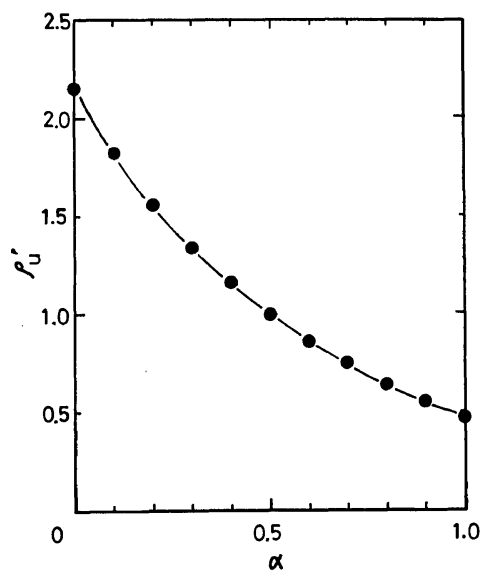

Figure 5. Simulation of scrambling effects. The $\alpha$ dependence for $\rho_{\mathrm{u}}^{\prime}$, assuming that $V_{\mathrm{v}}^{\text {iso }}=5.3 \times 10^{-6} \mathrm{~cm}^{-1}$ and $H_{\mathrm{v}}=2.7 \times 10^{-6} \mathrm{~cm}^{-1}$. with increasing $T$ and above $T_{\mathrm{g}}$, the value of $V_{\mathrm{v}}^{\text {iso }}$ increases and that of $H_{\mathrm{v}}$ approaches a constant value with increasing $T$. This is consistent with the published results. ${ }^{15-17}$ At 30 and $170^{\circ} \mathrm{C}$, we obtain $\alpha, H_{\mathrm{v}}, V_{\mathrm{v}}$, and $V_{\mathrm{v}}^{\text {iso }}$ by substituting the measured $R_{90}$ and $\rho_{\mathrm{u}}$ into eq $1-5$. In the range of $30-170^{\circ} \mathrm{C}$, we can estimate $\alpha$ and $V_{\mathrm{v}}$ by substituting reasonable values of ' $V_{\mathrm{v}}^{\text {iso }}$ and $H_{\mathrm{v}}$, and the observed $\rho_{\mathrm{u}}^{\prime}$ into eq 16.

The temperature dependence of $\alpha, V_{v}, V_{v}^{\text {iso }}$, and $H_{\mathrm{v}}$, corrected on the present assumption, are shown in Figure 6. The value of $\alpha$ shows a minimum near $T_{\mathrm{g}}$, whereas the trend of the $V_{\mathrm{v}}-T$ curve appears reasonable in view of the published results in the $30-170^{\circ} \mathrm{C}$ temperature range. This indicates that intense scrambling effects occur near $T_{\mathrm{g}}$ in the present PS system.

The results of the light scattering study on PS are summarized in Table I. The present $V_{v}^{\text {iso }}$ and $H_{\mathrm{v}}$ values are comparable to the previous reported values. The $V_{\mathrm{v}}^{\text {iso }}$ values below $T_{\mathrm{g}}$ have been calculated by substituting the reported $\beta$ value at $T_{\mathrm{g}}$ into eq $6{ }^{16,22}$ For the calculated $V_{\mathrm{v}}^{\text {iso }}$ and $H_{\mathrm{v}}$ values, there is relatively good

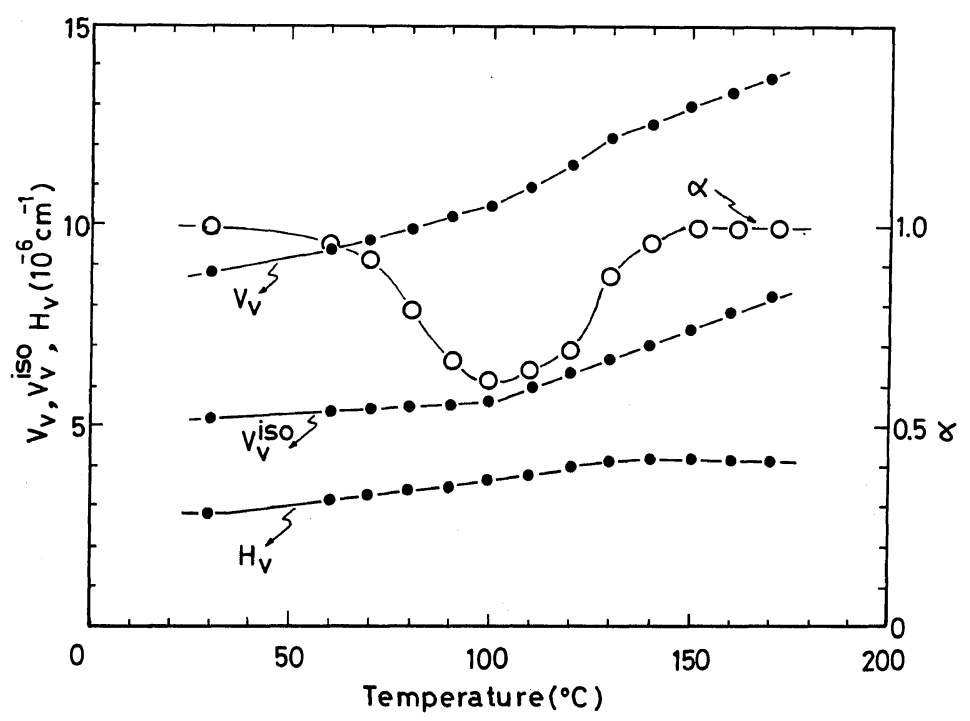

Figure 6. Temperature dependence of $\alpha, V_{v}, V_{\mathrm{v}}^{\text {iso }}$, and $H_{\mathrm{v}}$, corrected by $R_{90}^{\prime}, \rho_{\mathrm{u}}^{\prime}$, and the scrambling effects for pure PS $\left(\lambda_{0}=633 \mathrm{~nm}\right)$. 
Light Scattering Study on the Structure of Pure Polystyrene

Table I. Results of light scattering studies on PS

\begin{tabular}{|c|c|c|c|c|c|c|}
\hline Workers & $\frac{R_{90}}{10^{-6} \mathrm{~cm}^{-1}}$ & $\frac{V_{\mathrm{v}}^{\text {iso }}}{10^{-6} \mathrm{~cm}^{-1}}$ & $\frac{H_{\mathrm{v}}}{10^{-6} \mathrm{~cm}^{-1}}$ & $\frac{T}{{ }^{\circ} \mathrm{C}}$ & $\frac{\lambda_{0}}{\mathrm{~nm}}$ & Note \\
\hline$(C \& C)$ & 19.2 & 6.0 & 7.5 & 25 & 578 & $\begin{array}{l}\text { Obsd } \\
\alpha=0.75\end{array}$ \\
\hline \multirow{2}{*}{$(D \& F)$} & 13.8 & 6.0 & 5.0 & 25 & 578 & Obsd \\
\hline & 15.1 & 8.5 & 5.0 & 120 & 578 & Obsd \\
\hline \multirow[t]{6}{*}{ (This work) } & 8.5 & 5.3 & 2.7 & 30 & 633 & $\begin{array}{l}\text { Obsd } \\
\alpha=1.0\end{array}$ \\
\hline & 10.8 & 5.6 & 3.7 & 100 & 633 & $\begin{array}{l}\text { Estimate } \\
\alpha=0.60\end{array}$ \\
\hline & 13.0 & 7.8 & 4.2 & 170 & 633 & $\begin{array}{l}\text { Obsd } \\
\alpha=1.0\end{array}$ \\
\hline & 12.5 & 7.6 & 4.0 & 30 & 578 & $\alpha=1.0^{\mathrm{a}}$ \\
\hline & 15.5 & 8.0 & 5.3 & 100 & 578 & $\alpha=0.60^{\mathrm{a}}$ \\
\hline & 18.7 & 11.2 & 6.0 & 170 & 578 & $\alpha=1.0^{\mathrm{a}}$ \\
\hline$(C \& C)$ & 16.3 & 5.8 & 6.2 & 25 & 578 & Calcd \\
\hline$(\mathrm{D} \& \mathrm{~F})$ & $16.3-19.1$ & $5.8-7.8$ & $6.2-7.0$ & 25 & 578 & Calcd \\
\hline
\end{tabular}

a Evaluated from eq 6-7.

agreement with the experimental values by Claiborne and Crist, ${ }^{22,23}$ and Dettenmaier and Fischer. ${ }^{16}$ Our corrected results show that the $V_{\mathrm{v}}^{\text {iso }}$ values increased by $0-13 \%$ and the $H_{\mathrm{v}}$ value decreased by $35-44 \%$, compared with those calculated.

The corrected $V_{\mathrm{v}}^{\text {iso }}$ values in the present study are in relatively good agreement with those calculated and observed at $25^{\circ} \mathrm{C},{ }^{16,22}$ indicating PS glass to be in a frozen state near $T_{\mathrm{g}}$. Ruland ${ }^{17}$ in determining the temperature dependence of density fluctuation for PS by SAXS, found PS to be in a non-equilibrium state thermodynamically in a temperature range from $T_{\mathrm{g}}$ to about $T_{\mathrm{g}}-50$. Our $V_{\mathrm{v}}^{\text {iso }}$ is consistent with the SAXS result. As to the scrambling effects, we obtained $\alpha=1.0$ for PS glass at $30^{\circ} \mathrm{C}$ and $\alpha=0.60$ for PS rubber at $100^{\circ} \mathrm{C}$, respectively. These values indicate that PS rubber gives intense scrambling effects and is in a some partially oriented state, ${ }^{29}$ whereas in PS glass, scrambling effects cease to occur and this glass is a randomly oriented spheroid. These scrambling effects may be attributed to strained polymer molecules adhering to the
Table II. Comparison between the observed and calculated $\gamma_{0}^{2}$ values on PS and PMMA

\begin{tabular}{|c|c|c|c|}
\hline$\gamma_{0}^{2}(\mathrm{PS})$ & $\gamma_{0}^{2}$ (PMMA) & $T$ & \\
\hline $10^{-50} \mathrm{~cm}^{-6}$ & $10^{-50} \mathrm{~cm}^{-6}$ & ${ }^{\circ} \mathrm{C}$ & \\
\hline 3100 & 16 & 30 & Obsd (Our work) \\
\hline 4200 & & 100 & Estimate (Our work) \\
\hline 5500 & 320 & 25 & Obsd (D \& F) \\
\hline 2800 & 2 & & $\begin{array}{l}\text { Calcd }(T, A, \& F) \\
\text { Calcd (D \& F) }\end{array}$ \\
\hline
\end{tabular}

ampoule glass wall.

The corrected $H_{\mathrm{v}}$ value for PS glass, $4.0 \times 10^{-6} \mathrm{~cm}^{-1}$ at $\lambda_{0}=578 \mathrm{~nm}$, differs by 54 $20 \%$ from the experimental values obtained by Claiborne and Crist, and Dettenmaier and Fischer. This discrepancy may be due to the differences in the chain transfer agent used in the preparation of samples. By conducting the chain transfer reaction at a temperature above $T_{\mathrm{g}}$, the generation of microinhomogeneities due to the auto-acceleration effect and increase in polymerization rate may be suppressed. With the value of $H_{\mathrm{v}}$ and the number of 
monomer repeat units per $\mathrm{cm}^{3}$ inserted in eq 7 , the anisotropy value $\gamma_{0}^{2}$ for a monomer unit can be obtained. The results for $\gamma_{0}^{2}$ of PS and PMMA are summarized in Table II. If a randomly oriented anisotropic liquid is assumed for PS glass, we obtain $3.1 \times 10^{-47} \mathrm{~cm}^{6}$ for $\gamma_{0}^{2}$. This nearly equals the value evaluated by Tonelli, Abe, and Flory ${ }^{29}$ on the basis of the rotational isomeric state theory, suggesting that no ordered anisotropic structures induced by collisions, orientational correlation, or frozen strains, exists in wellannealed pure PS glass. Dettenmaier and Fischer reported the value of $\gamma_{0}^{2}$ for PS to be twice the calculated value. ${ }^{29}$ The $\gamma_{0}^{2}$. value for PS rubber, however, slightly increases more than that for PS glass and is comparable to the calculated value. This suggests that PS rubber is in a some partial oriented state, as a result of strained polymer molecules adhering to the ampoule glass wall. This adhesion between the polymer and ampoule glass wall may be markedly pronounced in the case of the relatively low-molecular weight polymer sample used in the present study.

\section{CONCLUSIONS}

Our light scattering data for PS glass prepared from a pure monomer and additives at a temperature above $T_{\mathrm{g}}$ are consistent with the scattering behavior expected for a supercooled liquid. From the temperature dependence of the $V_{v}^{\prime}, V_{v}^{\text {iso }}$, and $H_{v}^{\prime}$ components for pure PS in the 30 to $170^{\circ} \mathrm{C}$ range, the scrambling effects of the incident and scattered light radiation during transmission through the sample were found mainly near $T_{\mathrm{g}}$. These effects may be due to strained polymer molecules adhering to the ampoule glass wall as a result of the relatively low-molecular weight PS sample.

The value of $V_{v}^{\text {iso }}$ for PS glass was in relatively good agreement with the calculated value. This shows that PS glass is in a frozen state with thermal density fluctuation near $T_{\mathrm{g}}$. The value of $\gamma_{0}^{2}$ evaluated from the
$H_{\mathrm{v}}$ intensity for PS glass, assuming it to be a randomly oriented anisotropic liquid, nearly equals that according to the rotational isomeric state theory. This shows, suggested by the absence of scrambling effects, that PS glass does not exist in an ordered anisotropic region. Intense scrambling effects suggest PS rubber to be in a partially oriented state. Our experiment shows no evidence for the an ordered structure in pure PS glass, as in pure PMMA glass, but pure PS rubber has a partially ordered structure. This conclusion is based on the use of a relatively low-molecular weight pure PS sample very carefully prepared.

Acknowledgement. General assistance by Yuzo Katayama, Shigeo Nara, Toshikuni Kaino and Toshiro Hirai is greatfully acknowledged. The scattering experiment was initiated at a suggestion by Toshiro Hirai.

\section{REFERENCES}

1. H. M. Schleiniz, Int. Wire Cable Symp., 25, 352 (1977).

2. T. Kaino, M. Fujiki, S. Oikawa, and S. Nara, Appl. Opt., 20, 2886 (1981).

3. T. Kaino, M. Fujiki, and S. Nara, J. Appl. Phys., 52, 7061 (1981).

4. P. J. Flory, J. Chem. Phys., 17, 303 (1949).

5. W. Pechhold, Kolloid-Z. Z. Polym., 228, 1 (1968).

6. C. C. Kampf, J. Hofmann, and H. Kramer, Ber. Bunsenges, 74, 851 (1970).

7. G. S. Y. Yeh, J. Macromol. Sci., Phys., B6, 465 (1972).

8. R. E. Judd and B. Crist, J. Polym. Sci., Polym. Lett. Ed., 18, 717 (1980).

9. M. Dettenmaier and E. W. Fischer, Kolloid-Z. Z. Polym., 251, 922 (1973).

10. G. D. Patterson, J. Macromol. Sci., Phys., B12, 61 (1976).

11. A. B. Romberger, D. P. Eastman, and J. L. Hunt, J. Chem. Phys., 51, 3723 (1969).

12. E. A. Friedman, A. J. Ritger, and R. D. Andrews, $J$. Appl. Phys., 40, 4243 (1969).

13. G. D. Patterson, P. J. Carroll, and J. R. Stevens, J. Polym. Sci., 21, 613 (1983).

14. M. Fujiki, T. Kaino, and S. Oikawa, Polym. J., 15, 693 (1983).

15. E. W. Fischer, J. H. Wendorff, M. Dettenmaier, G. Lieser, and I. Voigt-Martin, J. Macromol. Sci., Phys., 
Light Scattering Study on the Structure of Pure Polystyrene

B12, 41 (1976).

16. M. Dettenmaier and E. W. Fischer, Makromol. Chem., 177, 1185 (1976).

17. W. Ruland, Pure Appl. Chem., 49, 905 (1977).

18. R. Simha, S. C. Jain, and A. M. Jamieson, Macromolecules, 15, 1517 (1982).

19. R. W. Coakley, R. S. Mitchell, J. R. Stevens, and J. L. Hunt, J. Appl. Phys., 47, 4271 (1976).

20. H. Lee, A. M. Jamieson, and R. Simha, Collect. Polym. Sci., 258, 545 (1980)

21. G. R. Alms, G. D. Patterson, and J. R. Stevens, J. Chem. Phys., 70, 2145 (1979).

22. C. Claiborne and B. Crist, Collect. Polym. Sci., 257, 457 (1979).

23. C. Claiborne and B. Crist, J. Polym. Sci., Polym. Phys. Ed., 17, 719 (1979).

24. R. W. Coakley, R. S. Mitchell, J. L. Hunt, and J. R. Stevens, J. Macromol. Sci., Phys., B12, 511 (1976).
25. C. M. Balik, A. M. Jamieson, and R. Simha, Collect. Polym. Sci., 260, 477 (1982).

26. J. V. Champion and P. Liddle, Polymer, 21, 1247 (1980).

27. J. R. Stevens, D. A. Jackson, and J. V. Champion, Mol. Phys., 29, 1893 (1975).

28. J. E. Guillet, R. S. Mitchell, E. Dan, and J. P. Valleau, J. Polym. Sci., Polym. Lett. Ed., 10, 625 (1972).

29. A. E. Tonelli, Y. Abe, and P. J. Flory, Macromolecuiles, 3, 303 (1970).

30. M. B. Huglin, "Light Scattering from Polymer Solution," Academic Press, New York, N. Y., 1972.

31. M. Kerker, "The Scattering of Light and Other Electromagnetic Radiation," Academic Press, New York, N. Y., 1972.

32. A. Einstein, Ann. d. Phys., 33, 1275 (1910). 